\title{
Factor Structure of the Center for Epidemiologic Studies Depression Scale in South Korea
}

\author{
Shuntaro Aoki' ${ }^{1}$ Akira Tsuda ${ }^{2}$, Satoshi Horiuchi3 ${ }^{3,4}$, Euiyeon Kim5, Mayu Naruse1, \\ Aki Tsuchiyagaito', Kwangshik Hong ${ }^{6}$ \\ ${ }^{1}$ Graduate School of Psychological Science, Health Sciences University of Hokkaido, Sapporo, Japan \\ ${ }^{2}$ Department of Psychology, Kurume University, Kurume, Japan \\ ${ }^{3}$ School of Psychological Science, Health Sciences University of Hokkaido, Sapporo, Japan \\ ${ }^{4}$ Japan Society for the Promotion of Science, Tokyo, Japan \\ ${ }^{5}$ Department of Education, Inha University, Incheon, Korea \\ ${ }^{6}$ Department of Elementary Education, Jeonju National University of Education, Jeonju, Korea \\ Email: s-aoki@hoku-iryo-u.ac.jp
}

Received 4 May 2014; revised 4 June 2014; accepted 4 July 2014

Copyright (C) 2014 by authors and Scientific Research Publishing Inc.

This work is licensed under the Creative Commons Attribution International License (CC BY).

http://creativecommons.org/licenses/by/4.0/

c) (i) Open Access

\begin{abstract}
Results of previous studies from North America reported that only 14 out of the 20 items from the Center for Epidemiologic Studies Depression Scale (CES-D) were required to assess negative affect, somatic symptoms, and anhedonia. However, it remains unclear whether this three-factor structure of the CES-D would be valid in South Korea. The purpose of this study is to examine the validity of the three-factor structure with a Korean version of the CES-D. The participants were Korean college students $(N=215)$, elementary school teachers $(N=234)$, and parents of elementary school students $(\mathrm{N}=\mathbf{2 3 0})$. Confirmatory factor analysis was performed to examine the scale's validity. Results indicated that the three-factor structure showed acceptable fit to data (comparative fit index = 0.95; root mean square error of approximation $=0.06$ ). The findings indicated that the three-factor structure of the CES-D was valid in South Korea.
\end{abstract}

\section{Keywords}

Depressive Symptoms, CES-D, Factor Structure, South Korea

\section{Introduction}

Managing depressive symptoms effectively has become an important social issue in South Korea. Cho, Nam,

How to cite this paper: Aoki, S., Tsuda, A., Horiuchi, S., Kim, E., Naruse, M., Tsuchiyagaito, A. and Hong, K. (2014) Factor Structure of the Center for Epidemiologic Studies Depression Scale in South Korea. Open Journal of Medical Psychology, 3, 301-305. http://dx.doi.org/10.4236/ojmp.2014.34031 
and Suh [1] studied the prevalence of depressive symptoms in Korean adults. They found that $25.3 \%$ of Korean adults had depression scores above the cutoff of 16 on the Korean version of the Center for Epidemiologic Studies Depression Scale (CES-D) and 8.6\% of those had depression scores above 25 [2]. Depressive symptoms refer to physical and mental states that are accompanied by a depressed mood [3]. In this study, depressive symptoms include negative affect, somatic symptoms, and anhedonia [4]. Negative affect is a depressed mood, which includes dysphoric mood or sadness. Somatic symptoms are somatic complaints such as sleep disturbance or fatigue. Anhedonia is lack of positive affect such as feeling good or happy. Individuals who have salient depressive symptoms usually have impaired psychosocial functioning [5]. Specifically, it has been suggested that differential psychotherapeutic and/or pharmacological treatments have different effects on negative affect, somatic symptoms, and anhedonia [6]. In a clinical setting, it is necessary to conduct treatments that are tailored to these specific symptoms because patients may experience them in different ways. Therefore, it is important to accurately assess negative affect, somatic symptoms, and anhedonia.

Recently, Carleton et al. [4] reported that only 14 items from the CES-D were required to accurately measure negative affect, somatic symptoms, and anhedonia. They removed the six items that were found to be superfluous. One item was excluded because a gender difference existed in its response pattern. Two other items were excluded since they only assessed interpersonal problems and not symptoms specific to depression [7]. The other three items were removed because they worsened the model's fit to the data. They proposed their own three-factor model of the CES-D in which negative affect, somatic symptoms, and anhedonia were measured with four, six, and four items. The model showed an acceptable fit to data, with the comparative fit index (CFI) and root mean square error of approximation (RMSEA) being 0.96 to 0.97 and 0.05 to 0.06 , respectively. The internal consistency reliability of each subscale was found to be acceptable, with Cronbach's alpha coefficients ranging from 0.74 to 0.90 for negative affect, 0.51 to 0.81 for somatic symptoms, and 0.73 to 0.86 for anhedonia. Furthermore, moderate to strong correlations were found among all three factors ( $r=0.59$ to 0.85 ). These results provided strong support for the idea that only 14 items of CES-D were required to assess negative affect, somatic symptoms, and anhedonia.

Unfortunately, the validity of the three-factor model has been tested only with North American participants [4]. Therefore, no study has ever tested this model with South Korean participants. Previous studies have reported the differences in response patterns between American and Korean participants to items on the CES-D [1]. For example, Cho and Kim (1998) reported that Korean participants scored lower on the anhedonia subscale than their American counterparts. Thus, for this theoretical model of the CES-D to gain credibility, it needs to be tested outside of North America (including South Korea). The purpose of this study is to examine whether the three-factor model developed by Carleton et al. [4] would be valid for South Korean participants.

\section{Method}

The institutional review board of the Kurume University approved this study. Participants in this study included 215 Korean college students, 234 elementary school teachers, and 230 parents of elementary school children. Data were collected at several elementary schools and one college. Participants included 169 men and 510 women. With regard to participants' age, $9.3 \%$ were in their $10 \mathrm{~s}, 34.6 \%$ were in their $20 \mathrm{~s}, 35.6 \%$ were in their $30 \mathrm{~s}, 16.2 \%$ were in their $40 \mathrm{~s}$, and $4.4 \%$ were 50 or older (Table 1 ). Researchers or their assistants distributed a questionnaire packet to each of the participants after they had been given permission from the school principals and class lecturers for distribution of the questionnaires. After getting an explanation about the purpose and voluntary nature of the survey, only those who agreed to participate completed the questionnaires. Data of most elementary school teachers and parents of elementary school students $(\mathrm{N}=418)$ were used in the study by Horiuchi, Tsuda, and Sakano [8]. Their study examined relationships between stress management and depressive symptoms in which the total scores of the Korean version of CES-D were used for analyses. The results of a confirmatory factor analysis of 14 items of the Korean version of the CES-D were not reported.

The questionnaire packet included the integrated Korean version of the Center for Epidemiologic Studies Depression Scale (CES-D), as well as several other measures that tested the paricipants' abilities to manage stress. The Korean version of the CES-D consisted of 20 items [9]. Higher total scores reflected higher levels of depressive symptoms. The internal consistency reliability and validity coefficients were acceptable [8]. For this study, only 14 of the 20 items were used for analyses.

Data of the CES-D was analyzed as follows. The confirmatory factor analysis was conducted to examine 
Table 1. Demographic data of participants.

\begin{tabular}{ccccc}
\hline & \multicolumn{4}{c}{$\mathrm{N}(\%)$} \\
\hline Sex & Students $(\mathrm{N}=215)$ & Teachers $(\mathrm{N}=234)$ & Parents $(\mathrm{N}=230)$ & All $(\mathrm{N}=679)$ \\
Male & $68(31.6)$ & $59(25.2)$ & $42(18.3)$ & $169(24.9)$ \\
Female & $147(68.4)$ & $175(74.8)$ & $188(81.7)$ & $510(75.1)$ \\
Age & & & & \\
$17-20$ & $63(29.3)$ & - & - & $63(9.3)$ \\
$20-29$ & $148(68.8)$ & $82(35.0)$ & $5(2.2)$ & $235(34.6)$ \\
$30-39$ & $4(1.9)$ & $87(37.2)$ & $150(65.2)$ & $241(35.5)$ \\
$40-49$ & - & $38(16.2)$ & $72(31.3)$ & $110(16.2)$ \\
$50-74$ & - & $27(11.6)$ & $3(1.3)$ & $30(4.4)$ \\
\hline
\end{tabular}

whether the three-factor model developed by Carleton et al. [4] would be valid in South Korea. The CFI and RMSEA were used to evaluate how well the model fit the data. CFI values higher than 0.95 indicate that it was an excellent fit [10]. An RMSEA below 0.08 represents a good fit between the model and data [11]. Finally, the reliability was evaluated in terms of internal consistency. A Cronbach's alpha coefficient was calculated for each subscale as an indicator of internal consistency.

\section{Results}

The mean score and standard deviation of each item for the Korean version of the CES-D are shown in Table 2. A confirmatory factor analysis was then conducted to examine whether the data were consistent with the threefactor model's constructs. This model showed an acceptable fit to data (CFI $=0.95$, RMSEA $=0.06)$. Factor loadings ranged from 0.41 to 0.86 (Figure 1). There were moderate to strong correlations between the three factors, with their correlation coefficients ranging from 0.52 to 0.94 (Figure 1). A Cronbach's alpha coefficient was calculated for each subscale. The alpha coefficients for the three factors were 0.87 for somatic symptoms, 0.80 for negative affect, and 0.76 for anhedonia.

\section{Discussion}

The purpose of this study is to examine whether the three-factor model developed by Carleton et al. [4] would be supported with a sample of South Korean adults. It showed an acceptable fit to data provided by a sample of Korean adults. The CFI and RMSEA values clearly exceeded acceptable values. In addition, the findings were consistent with the results of Carleton et al. [4], where moderate to strong correlations were found for negative affect, somatic symptoms, and anhedonia. These results suggested that Carleton et al.'s [4] model could be used with South Korean samples.

The results of this study provided support for the rationale to divide the 14 items from the CES-D into three types of depressive symptoms (negative affect, somatic symptoms, and anhedonia) in South Korea. The validity of the three-factor structure including 14 items from the CES-D had only been confirmed in North America [4]. The results of this study extended the literature in this field by providing some initial evidence that of the threefactor model has validity in South Korea. This extension is important because, in South Korea, like in many other countries, managing depressive symptoms has become an important special issue [1]. Increased effort to tailor treatment to specific aspects of depressive symptoms has been called for Sharpley and Bitsika [6]. This means that a cost-effective scale needs to be developed to assess patients for negative affect, somatic symptoms, and anhedonia. The results of this study provide evidence that 14 items of CES-D could be used to assess these symptoms in South Korea.

There were several limitations in this study that should be noted. For example, this study only focused on college students, elementary school teachers, and parents of elementary school students. Therefore, it remains to be 


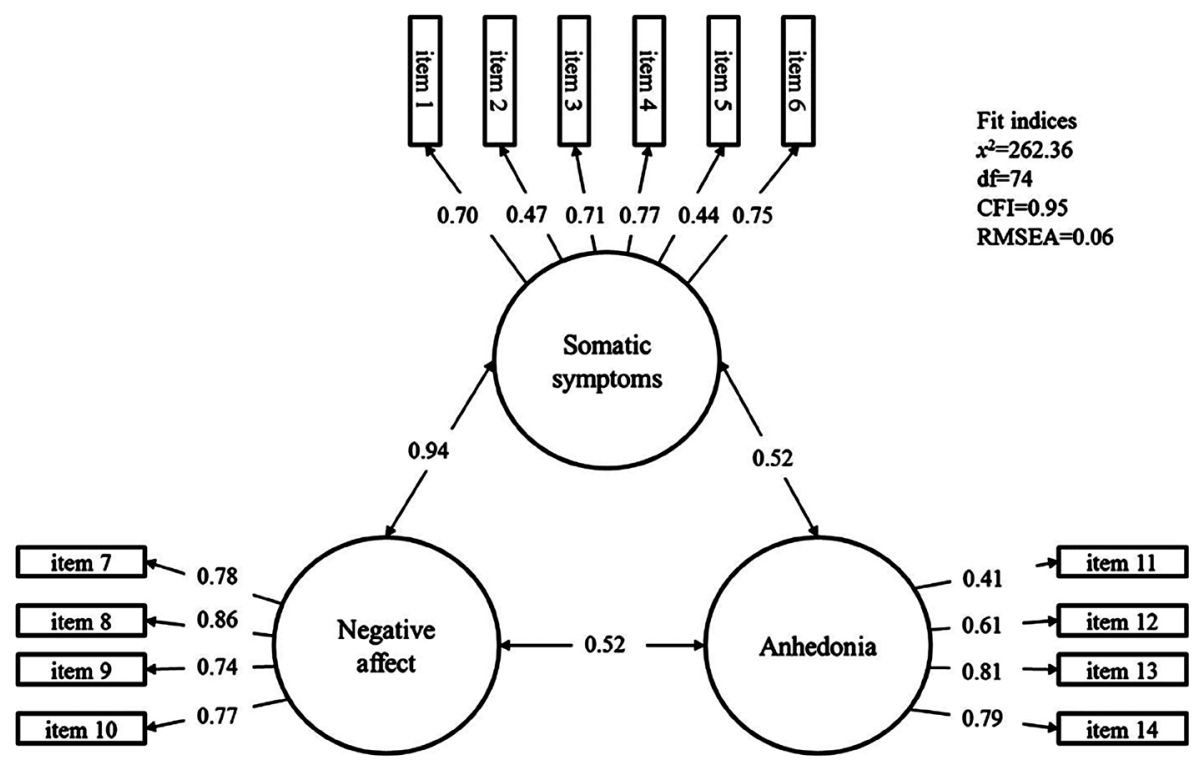

Figure 1. Pathdiagram of the three-factor model of the Korean version of the CES-D. Note: RMSEA = root mean of square error of approximation, CFI = comparative fit index.

\section{Table 2. Descriptive statistics.}

\begin{tabular}{|c|c|c|c|c|}
\hline Item & & & $M$ & $S D$ \\
\hline \multirow[t]{7}{*}{ Factor 1} & & Somatic symptoms (Cronbach’s alpha $=0.87)$ & & \\
\hline & 1 & I was bothered by things that usually don't bother me. & 0.93 & 0.79 \\
\hline & 2 & I did not feel like eating; my appetite was poor. & 0.51 & 0.70 \\
\hline & 3 & I had trouble keeping my mind on what I was doing. & 0.77 & 0.78 \\
\hline & 4 & I felt that everything I did was an effort. & 0.83 & 0.84 \\
\hline & 5 & My sleep was restless. & 0.57 & 0.82 \\
\hline & 6 & I could not get "going". & 0.61 & 0.84 \\
\hline \multirow[t]{5}{*}{ Factor 2} & & Negative affect (Cronbach’s alpha $=0.80$ ) & & \\
\hline & 7 & I felt that I could not shake off the blues, even with the help from family or friends. & 0.67 & 0.82 \\
\hline & 8 & I felt depressed. & 0.72 & 0.83 \\
\hline & 9 & I felt lonely. & 0.57 & 0.79 \\
\hline & 10 & I felt sad. & 0.56 & 0.76 \\
\hline \multirow[t]{5}{*}{ Factor 3} & & Anhedonia (Cronbach’s alpha $=0.76)$ & & \\
\hline & 11 & I felt that I was just as good as other people. & 1.63 & 0.88 \\
\hline & 12 & I felt hopeful about the future. & 1.46 & 0.92 \\
\hline & 13 & I was happy. & 1.32 & 0.87 \\
\hline & 14 & I enjoyed life. & 1.40 & 0.85 \\
\hline
\end{tabular}

Note: $M=$ Mean score, $S D=$ Standard Deviation.

seen whether the results could be generalized to other Korean populations, since the study's sample did not include any clinically depressed participants. Therefore, it was unclear whether the findings could be generalized to individuals who had been diagnosed with major depressive disorders. More research is needed to study indi- 
viduals who meet the criteria for major depressive disorders using structured interviews.

\section{Conclusion}

In summary, this study provides evidence that the three-factor model of 14 items in CES-D is valid in South Korea. Depressive symptoms include negative affect, somatic symptoms, and anhedonia [4]. However, since there was no tool to simultaneously assess the three depressive symptoms in South Korea, the three-factor model of CES-D is assumed to be useful for the South Korean population.

\section{References}

[1] Cho, M.J. and Kim, K.H. (1998) Use of the Center for Epidemiologic Studies Depression (CES-D) Scale in Korea. Journal of Nervous and Mental Disease, 186, 304-310. http://dx.doi.org/10.1097/00005053-199805000-00007

[2] Cho, M.J., Nam, J.J. and Suh, G.H. (1998) Prevalence of Symptoms of Depression in a Nationwide Sample of Korean Adults. Psychiatry Research, 81, 341-352. http://dx.doi.org/10.1016/S0165-1781(98)00122-X

[3] American Psychiatric Association (2013) Diagnosis and Statistical Manual of Mental Disorder 5. Washington DC.

[4] Carleton, R.N., Thibodeau, M.A., Teale, M.J.N., Welch, P.G., Abrams, M.P., Robinson, T. and Asmundson, G.J.G. (2013) The Center for Epidemiologic Studies Depression Scale: A Review with a Theoretical and Empirical Examination of Item Content and Factor Structure. PloS One, 8, Article ID: e58067. http://dx.doi.org/10.1371/journal.pone.0058067

[5] Judd, L.L., Akiskal, H.S. and Paulus, M.P. (2003) The Role and Clinical Significance of Subsyndromal Depressive Symptoms (SSD) in Unipolar Major Depressive Disorder. Journal of Affective Disorders, 45, 5-18. http://dx.doi.org/10.1016/S0165-0327(97)00055-4

[6] Sharpley, C.F. and Bitsika, V. (2013) Differences in Neurobiological Pathways of Four "Clinical Content” Subtypes of Depression. Behavioural Brain Research, 256, 368-376. http://dx.doi.org/10.1016/j.bbr.2013.08.030

[7] Schafer, A.B. (2006) Meta-Analysis of the Factor Structures of Four Depression Questionnaires: Beck, CES-D, Hamilton, and Zung. Journal of Clinical Psychology, 62, 123-146. http://dx.doi.org/10.1002/jclp.20213

[8] Horiuchi, S., Tsuda, A. and Sakano, Y. (2013) Relationships between Practicing Effective Stress Management and Depressive Symptoms. Japanese Journal of Stress Sciences, 27, 234.

[9] Chon, K.K., Choi, S.C. and Yang, B.C. (2001) Integrated Adaptation of CES-D in Korea. Korean Journal of Health Psychology, 6, 59-76.

[10] Hu, L.T. and Bentler, P.M. (1999) Cutoff Criteria for Fit Indexes in Covariance Structure Analysis: Conventional Criteria versus New Alternatives. Structural Equation Modeling: A Multidisciplinary Journal, 6, 1-55. http://dx.doi.org/10.1080/10705519909540118

[11] MacCallum, R.C., Browne, M.W. and Sugawara, H.M. (1996) Power Analysis and Determination of Sample Size for Covariance Structure Modeling. Psychological Methods, 1, 130-149. http://dx.doi.org/10.1037//1082-989x.1.2.130 
Scientific Research Publishing (SCIRP) is one of the largest Open Access journal publishers. It is currently publishing more than 200 open access, online, peer-reviewed journals covering a wide range of academic disciplines. SCIRP serves the worldwide academic communities and contributes to the progress and application of science with its publication.

Other selected journals from SCIRP are listed as below. Submit your manuscript to us via either submit@scirp.org or Online Submission Portal.
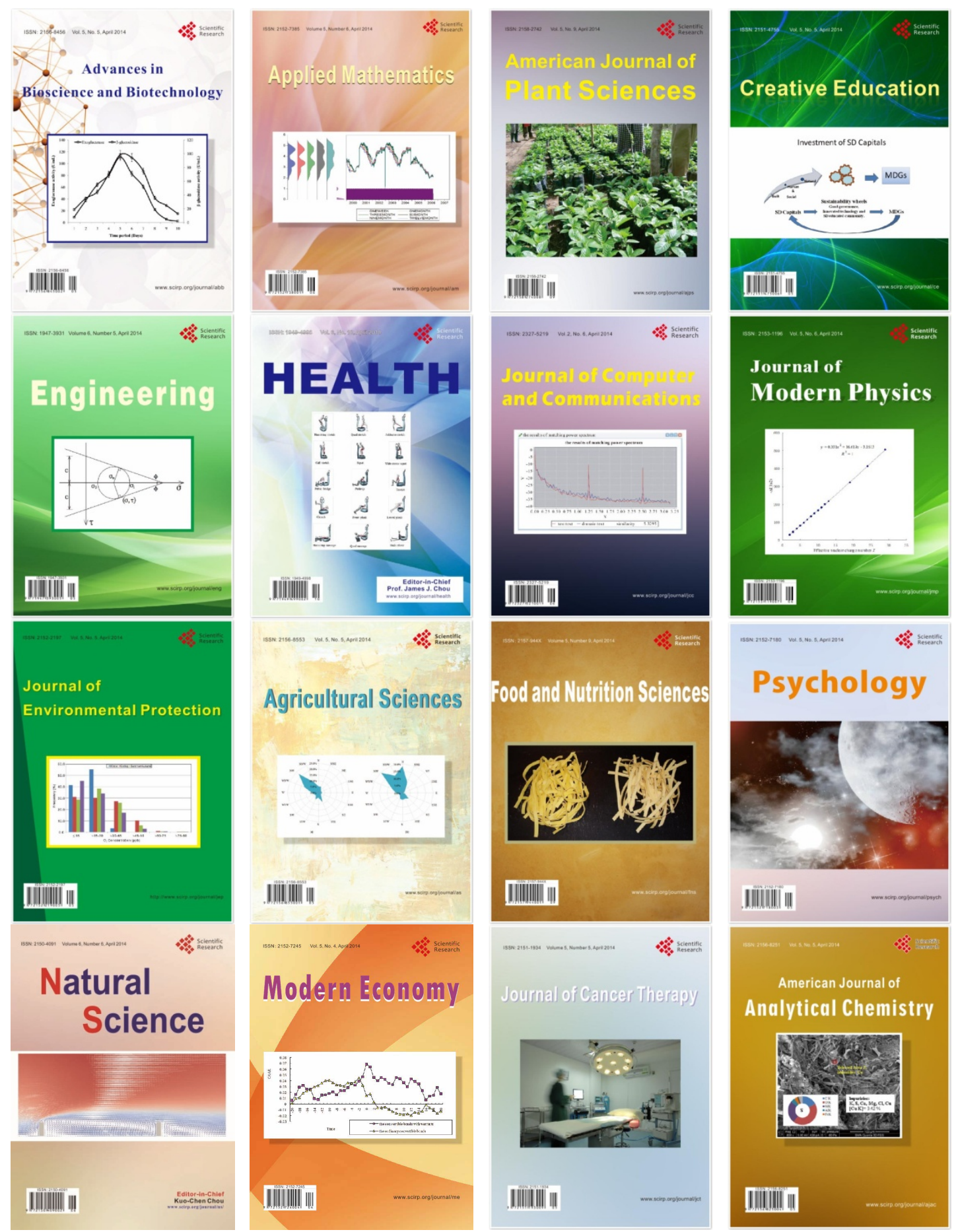